\title{
Climate Change and Society: Toward Online Pedagogy
}

\author{
Jennifer Kelly, Aaron McCright, and Thomas Dietz \\ Michigan State University, East Lansing, United States
}

\begin{abstract}
Climate change, one of the most important social problems of the twenty-first century, challenges pedagogy to incorporate complex themes from social and biophysical sciences. We propose an approach to a course on "Climate Change and Society" grounded in pedagogical research. Integrating the development of higher-level learning skills into course learning objectives, we suggest such a course be implemented online to take advantage of the virtual teaching and learning tools available to educators of climate change and as a way to actively engage the learner, thus using online pedagogy as a key element in learning that spans social and biophysical sciences.
\end{abstract}

Keywords: biological sciences, climate change, learning, pedagogy, physical sciences, social sciences, teaching

\section{Introduction}

Knowledge of climate science and understanding of climate change among the United States' (U.S.) general public (e.g., Marquart-Pyatt et al., 2011; McCright \& Dunlap, 2011; Reynolds et al., 2010), among U.S. college students (e.g., Hartley et al., 2011), and even among U.S. college students in the STEM disciplines of science, technology, engineering, and mathematics (e.g., Sterman \& Sweeney, 2007) is weak at best. This has much to do with the fact that the science of climate change is exceedingly difficult for educators and other communicators to teach and for students and audiences of all ages to learn (e.g., Boyes \& Stanisstreet, 2001; Coyle, 2005; U.S. National Research Council, 2007, 2011). A recent study finds that instructors of undergraduates need ongoing pedagogical support to effectively teach climate change (Kirk et al., 2014). These challenges are heightened for climate change courses grounded primarily in the social sciences. While such courses are clearly needed, social science instructors rarely have sufficient expertise in the biological and physical science aspects of climate change.

$1 \quad$ Corresponding author: kellyj24@msu.edu. 
Recently the scientific community has refocused to explicitly integrate the physical, biological, and social sciences for the study of climate change (U.S. National Research Council, 2010a, 2010b). At the same time, public discourse on climate change is shifting more toward "real-time Internet and news media communication" (Hamilton, 2012). This raises important challenges and opportunities for pedagogy in social science, an area with considerable scholarship on climate change but with little cohesion and consistency in its teaching on the topic. The opportunity to teach insights on the social drivers, dynamics, and impacts of climate change to post-secondary students is appealing. Yet, a social science course on climate change brings with it some complexities that are different from those faced in many other social science courses. One of these is the biological and physical science content that must also be conveyed in such a course. We cannot expect social science instructors to become experts in the complex physical and biological aspects of climate change, but neither can these topics be ignored. For an undergraduate course to integrate biophysical and social science information, methods, and skills is rare at best, but that does not discount the fact that such efforts are crucial for students to have a more holistic understanding of climate change.

One emerging way to address this challenge in a social science course is to integrate online education modules dealing with climate change from the physical and biological sciences. Clark-Ibáñez and Scott (2008) note that a key advantage to online teaching is that many valuable learning materials are already online. Examples relevant to a course on climate change and society are abundant, as the U.S. National Aeronautics and Space Administration (NASA) (climate.nasa.gov/resources/education), U.S. National Oceanic and Atmospheric Administration (NOAA) (www.climate. gov/\#climateWatch), U.S. National Science Foundation (www.exploratorium. edu/climate/), U.S. National Climate Assessment (www.climate.gov/ teaching/2014-national-climate-assessment-resources-educators), and U.S. National Academies (nas-sites.org/americasclimatechoices)_including Koshland Science Museum's Earth Lab (koshland-science-museum.org/explore-thescience/earth-lab) - have made robust investments in climate change education resources in recent years. ${ }^{2}$ Thus, what was otherwise a major challengeincorporating non-social science material into a social science course-becomes an opportunity to make effective use of existing online resources.

\footnotetext{
2 The list of internet resources is focused on the U.S. While climate change is a topic that inevitably engages discussions of global issues and an international perspective, we have designed our course assuming the majority of students will be from the U.S. and thus need examples grounded in the U.S. to complement international perspectives. But the basic pedagogical ideas we present can be generalized. Indeed, having a significant number of non-U.S. students in the course can aid in showing the variation across world regions in the effects of and possible responses to climate change.
} 
Here we consider how effective pedagogy in the social sciences can be developed while using such materials. Our focal question is: How can we best cultivate higher-order thinking skills using online climate change education modules? While there is very little literature on effective social science climate change education, we aim to develop an initial set of concepts and approaches by drawing on existing literature from social science and STEM education.

\section{The special challenges of climate change pedagogy}

Howard (2010, p. 91) identifies the essence of the pedagogical challenges we face:

How do we go about changing students' definitions of the classroom from a passive environment to an active one? How do we create a shift from surface learning to deep learning? We will need an interdisciplinary approach and to learn from the successes and failures of other disciplines in promoting learning.

For our online course on "Climate Change and Society," we meet these challenges through a critically engaged approach that intentionally integrates the physical and biological sciences with the social sciences. Given much scholarship of teaching and learning is disciplinary in nature, we recognize both the challenges and opportunities of teaching a course on climate change and society (e.g., McCright, 2012).

Contemporary assessments of climate science emphasize the necessity of interdisciplinary understanding (U.S. National Research Council, 2010a). The seven principles of climate science literacy developed by NOAA and NASA convey this interdisciplinarity (Table 1). The first five principles listed in the table must be addressed during social science instruction, as they provide context for understanding the human dimensions of the problem (the last two principles).

Table 1. Seven principles of climate science literacy

\begin{tabular}{|l|l|}
\hline 1. & The sun is the primary source of energy for Earth's climate system. \\
\hline 2. & Climate is regulated by complex interactions among components of the earth system. \\
\hline 3. & Life on Earth depends on, is shaped by, and affects climate. \\
\hline 4. & Climate varies over space and time through both natural and human-made processes. \\
\hline 5. & $\begin{array}{l}\text { Our understanding of the climate system is improved through observations, theoretical } \\
\text { studies, and modeling. }\end{array}$ \\
\hline 6. & Human activities are impacting the climate system. \\
\hline 7. & Climate change will have consequences for the earth system and human lives. \\
\hline
\end{tabular}

Source: U.S. Global Change Research Program (2009). 
Any course guided by these principles will have to integrate social, physical, and biological sciences into its pedagogy. We agree with Hartley and colleagues $(2011$, p. 65) that a grounding in the physical and biological science principles of climate change are "essential skill[s] for scientific literacy," and these principles cannot be ignored in social science courses on climate change. Yet, we know that biophysical science educators still grapple with how best to teach vital but complex subjects such as the carbon cycle (Hartley et al., 2011) and the dynamics of stocks and flows (Sterman \& Sweeney, 2007). We suggest that online materials - especially simulations that students can manipulate, such as those at the Koshland Science Museum's Earth Lab ${ }^{3}$ - are likely to prove quite useful for such subjects, complementing the skills of the social science instructor with those of pedagogical efforts of climate science educators.

To make effective use of these materials and advance the social science pedagogy of climate change, social science educators must draw upon the best practices in biophysical science and online pedagogy. We note that while we have developed this approach around an entirely online course, the use of online materials and our general points follow for a course that is either a hybrid of online and faceto-face materials or a face-to-face course that uses some online materials. We are not arguing that online only is inherently superior for integrating climate change into a social science course, merely that online materials, properly deployed, can help meet some of the core challenges of a social science course that must incorporate physical and biological science materials.

\section{Effective climate change pedagogy in an online classroom}

We emphasize two pedagogical "best practices" - teaching critical-thinking skills and engaging with our learners - as guides for how online modules can be used to integrate key climate change concepts into a social science course. These principles are already deployed in many social science classrooms, but we highlight them here as both special and essential for teaching climate change online.

\section{Critical-thinking skills}

Although educators often acknowledge the importance of critical thinking, this does not easily translate into skills taught to students. In fact, in a study assessing critical thinking in California universities, Paul and colleagues (1997, p. 18) found that although $89 \%$ of education, arts, and science faculty reported the

3 koshland-science-museum.org/explore-the-science/earth-lab. 
importance of critical thinking in their instruction, only $19 \%$ could explain it, and only $9 \%$ were teaching it. In response to pedagogical gaps in teaching critical-thinking skills, Anderson and Krathwohl (2001) developed a taxonomy of cognitive learning, based on earlier work by Bloom (1956). This taxonomy can be translated into educational objectives, with application, analysis, synthesis, and evaluation as the basis of critical-thinking skills. In addition, knowledge and comprehension, while not critical-thinking skills in themselves, are necessary for competence and to move into higher-order thinking. Importantly, using, valuing, and teaching critical-thinking skills are all distinct actions. For institutions, departments, and faculty to help students develop criticalthinking skills and dispositions, it would be helpful to implement a specific model of critical thinking that then would be used consistently in instruction. Such a model is necessary if students are to be able to change their deep-seated patterns of thinking and develop true critical-thinking behaviors. ${ }^{4}$

Part of critical thinking requires the ability to synthesize, connect, and coherently integrate new knowledge within pre-existing paradigms. Climate change educators urge a move toward a more comprehensive approach to teaching and learning, where concepts are understood in connection with one another rather than as individual units (Hartley et al., 2011; McCright et al., 2013). Within social science, connections among prior knowledge, life experiences, and course content are a sign of deep learning and are encouraged in the classroom (McKinney et al., 2004, p. 45). Godfrey (2015) uses an earth community paradigm in her course on Society and Climate Change to underscore the interconnectedness of the social and natural world. She implemented creative learning activities such as the problem tree, a concept-mapping activity designed to encourage in-depth discussions and collective decisions through interactive analytical processes in a group setting. ${ }^{5}$ Dole and Bloom (2009, p. 9) apply an online inquiry-based design to encourage higher-order learning outcomes, finding that it enables students to collaborate, reflect, mentor, and problem solve and "require[s] learners to integrate past experience and current knowledge with new knowledge and experience to reflect on and create meaningful connections with course content." Finally, others find peer learning to facilitate the connection of different knowledge systems (Batzli et al., 2006).

\footnotetext{
4 Resources to foster such an endeavor can be found at www.criticalthinking.org.

5 For more ideas on a Society and Climate Change course see Godfrey (2015), who implemented creative activities in her face-to-face classroom that could be transformed for an online course. Her teaching approach is holistic and promotes active learning in the context of climate change.
} 


\section{Engaging with our learners}

Faculty and administrators increasingly promote active learning in which students learn by doing something (e.g., Christiansen \& Fischer, 2010; Godfrey, 2015; Obach, 2009; Pedersen, 2010; Persell, 2004), while the best practices of online learning in social science urge instructors to "increase motivation and engagement" among learners (McKinney, 2010, p. 1). In addition to fostering active rather than passive students, engaged learning may facilitate the development of analytical skills for higher-order learning. For example, Dowell (2006) engages students on waste issues by having them collect garbage, analyze it, and write an essay based on their analysis - linking theory to everyday life. Dowell (2006, p. 155) finds that the exercise "leaves a lasting impression and may pique interest in viewing the world through a sociological lens." As a best practice of online learning, Boettcher and Conrad (2010) suggest that a course address core concepts in a way that requires students to re-apply them in different contexts, at different levels of comprehension, and with different online tools. Batzli and colleagues (2006) propose that students gather their own data when attempting to solve complex real-world problems. This provides a foundation for students to connect their pre-existing conceptual framework with new knowledge.

Not surprisingly, scholars identify online discussions as a best practice (Boettcher \& Conrad, 2010, p. 37; McKinney, 2010, p. 1). Online discussions provide an additional way for students to interact with each other and engage with a course - supplementing and extending in-class activities. For example, Pearson (2010) highlights the importance of an online classroom where knowledge is shared and meanings are renegotiated in online discussions. This is different from much of the writing that occurs in a traditional course design and in many online approaches, whereby students' writing is read mostly-if not entirelyby the instructor alone. In their review of best practices of online discussions, Boettcher and Conrad (2010, p. 37) suggest that successful student posts should invite responses, questions, discussions, and reflection. Persell (2004) finds that online discussions produce greater participation, engagement, and interaction compared to the traditional course design. Students spend more time analyzing and reflecting on the questions being posed before providing written feedback and are more likely to feel as though they are part of a classroom dialogue (Clark-Ibáñez \& Scott, 2008). This suggests that online discussions have the ability to create supportive online communities - another best practice of online learning (Boettcher \& Conrad, 2010, p. 37). Additional research suggests that benefits of online discussions are more likely to occur when these forums are graded (Swan et al., 2006). 
Enhanced learning outcomes may be achieved in the online classroom with a more frequent, reflective, and enriched dialogue (Wright \& Lawson, 2005). For example, Roper (2007) found that students receiving high grades in an online course claimed that their success was due, in part, to making the most of online discussions, asking questions useful to learning, and making connections with fellow students. Finally, Kortemeyer (2007) finds that online discussions can be a diagnostic tool in assessing student beliefs, attitudes, expectations, and approaches to course content, enabling these forums to serve as more than a teaching strategy.

These tenets of best practices guide us when designing a course on climate change and society. From this brief review of pedagogical literature we know that higher-level cognitive skills help students learn about complex, realworld problems such as climate change. Further, this review makes clear the importance of actively engaging students. Instructors of more traditional topics in the social sciences have spent years developing ways to actively engage students. Climate change, a subject that involves the biophysical sciences as well as social sciences, will require a special effort to ensure learning that meets the criteria not only for engagement, but critical-thinking skills as well.

\section{Climate change and society: The course}

We now explain a design for integrating these best practices for online teaching and learning into an online course on climate change and society. Using Bloom's taxonomy of education objectives (Anderson \& Krathwohl, 2001) and the seven principles of climate change literacy (U.S. Global Change Research Program, 2009), we propose a set of specific learning objectives to guide instructors (Table 2). Following Biggs (1999), these objectives begin with action verbs, signaling to instructors and students alike how such objectives may later be assessed. While we acknowledge there are various ways to implement these objectives, we outline examples of learning activities that could be used in an online class on climate change and society. While we urge instructors to design their own tailored assessments, we suggest how student learning may be assessed for each of these activities. We note that peer review may serve as the first stage of assessment (Phelan, 2012) and that some of the assignments meet more than one course objective. 
Table 2. Course objectives for climate change and society

\begin{tabular}{|l|l|}
\hline 1. & Identify, classify, and assess the key biophysical and social processes driving the climate. \\
\hline 2. & Identify and explain key vulnerabilities and/or adaptation potential for a selected relevant case. \\
\hline 3. & Apply learned insights to a new case. \\
\hline 4. & $\begin{array}{l}\text { Assess the costs and benefits for relevant stakeholder groups of the major strategies for } \\
\text { limiting climate change. }\end{array}$ \\
\hline 5. & Explain decision-making under uncertainty and how it is relevant in analyzing policy choices. \\
\hline 6. & Evaluate local, state, regional, national, and global roles in the context of climate change. \\
\hline 7. & Using higher-order thinking skills, explain climate change. \\
\hline
\end{tabular}

\section{Objective 1: Identify, classify, and assess the key biophysical and social processes driving the climate}

Since social science students may be inclined to be passive during a focus on biophysical science content, climate change and society course instructors should therefore work especially hard to promote active learning during that time. Thus, while a mini lecture on the carbon cycle may be necessary to identify the key biophysical processes driving the climate, it can easily be supplemented with think-pair-share activities (Bataineh, 2015) or online one-minute papers (Erickson \& Erickson, 2013) to spur student engagement. We suggest that students then identify - and classify (e.g., land use, fossil fuels consumption) their personal life activities that drive climate change.

After doing so, students would complete an ecological footprint quiz, which calculates individuals' personal impact on the ecosystem with answers to questions about their living, transport, and dietary behaviors, for example. ${ }^{6}$ Students would then reflect upon the results of their ecological footprint quiz. They would compare these results, which are based on scientific research, to their earlier estimates to better understand their prior knowledge in this area. Reflection upon this comparison may also help students better understand how their personal behaviors (e.g., consuming processed versus local food) impact ecological change. Further, students would identify three behavioral changes that would significantly reduce their ecological footprint. This assignment is similar to what Christiansen and Fischer (2010) call "walk the talk" in their course "Sustainable Cities in North America."

\footnotetext{
6 For an overview of ecological footprints including definitions, measures, and calculators, see Čuček et al. (2012). With a population of undergraduate students, it is important to use ecological footprint calculatorssuch as www.earthday.org/footprint-calculator - that relate moderately well to common student living conditions (e.g., dorm/rental residences, cafeteria dining). Note that while we endorse footprint calculators for their pedagogical value, we are also aware that there is considerable variation across such calculators in their assessment of individual impacts on the environment.
} 
Obach (2009) has students post their ecological footprint quiz results and reflections on a discussion board for peer review and commentary, and we also recommend this. Further, students would respond to the posts of two other students for additional experience in analyzing the processes driving climate change. Such activities can help students see the impact of their (and their peers') individual choices and behaviors on the climate and evaluate which choices and behaviors have a greater or lesser impact on the climate. The peer review process serves as a stage of formative assessment reflections. Record-keeping activities produced from this project are tools to help students understand how social structural and cultural factors impact the carbon cycle. Students would be assessed on how well they accomplish the objectives of identifying, classifying, and assessing key processes driving the climate. This activity also provides an opportunity for students to consider their role as consumers and as citizens.

\section{Objective 2: Identify and explain key vulnerabilities and/or adaptation potential for a selected relevant case; Objective 3: Apply learned insights to a new case; Objective 4: Assess the costs and benefits for relevant stakeholder groups of the major strategies for limiting climate change}

After lecturing on key vulnerabilities and adaptation potential using case studies, we suggest that students work in a team with an example problem (e.g., invasive species; Batzli et al., 2006) as part of the instruction as yet another way to promote critical thinking. The Colorado River Water Supply Module (CRWSM) from the Encyclopedia of Earth website ${ }^{7}$ is an example problem that could be used to meet Objective 2. In this module, students would become acquainted with the Colorado River watershed by looking at a summary of graphs, charts, and data. The assignment built around the module asks the students to assess the data to determine if the climate is changing and then explain their answer. Students then would be asked to review, reflect upon, and assess water allocation, enabling them to connect society, policy, and science by explaining the outcomes, while assessing who is using the water for which purposes.

Next, the student teams would work with a new case ${ }^{8}$ in order to apply their learned knowledge from the lecture and the CRWSM. This exercise will meet Objectives 3 and 4 . To meet Objective 3 students would proceed through the same steps as in the CRWSM, but this time with a new case of their choice. To meet Objective 4, students would assess the costs and benefits for limiting

7 The module is found at www.eoearth.org/resources/view/166680/?topic $=54424$.

8 UNESCO has a list of case studies from which students can choose: whc.unesco.org/en/news/319. 
climate change from the perspective of the relevant stakeholder groups in their specific case study. The student teams would then post their analyses for their new case to the class discussion forum. Each student would then individually review and provide feedback (via clarifying and analytical questions) on one other team's post, again using the peer review process as a form of formative assessment (Phelan, 2012). Students would be assessed based on their effective use of higher-order thinking skills stated in the objectives: identifying, explaining, applying, and assessing in connections with key vulnerabilities, adaptation, and mitigation strategies of coupled human and natural systems to climate change.

\section{Objective 5: Explain decision-making under uncertainty and how it is relevant in analyzing policy choices}

Following a lecture that defines and identifies issues in "decision-making under uncertainty" using case studies, we suggest one way to implement an active lesson is to have students examine media coverage of climate change. For example, following Dowell's (2006) lesson design, students would collect, analyze, and write about the content of comments by political officials and scientists in climate change news articles found in major newspapers or other media. After analysis, students would explain the issues in decision-making under uncertainty and how those decisions impact policies. Such explanations would then be posted to the discussion board where they would be reviewed by two peers. This allows students to work on their problem-solving and analytical reasoning skills in a communicative and engaged way, and practice their skills of providing and receiving feedback, while applying what they learned in the lecture to other contexts. Students would be assessed on their ability to explain, in their own words, the scientific uncertainty underlying one or more policy decisions, the concerns with scientific uncertainty, and how the concerns and uncertainty impact policy.

\section{Objective 6: Evaluate local, state, regional, national, and global roles in the context of climate change}

Following a lecture that defines, identifies, and evaluates economic and policy (adaption and mitigation) solutions to climate change, students would be encouraged to review information on these solutions using the Encyclopedia of Earth website to generate ideas for a paper. ${ }^{9}$ In this paper, they would make

9 The Encyclopedia of Earth has the structure of a wiki with opportunities for viewers to comment. But article content is peer reviewed and suggested changes are not made unless the editors and peer reviewers concur that such changes are scientifically appropriate (www.eoearth.org/topics/view/51cbfc8cf702fc2ba812cc93/). 
a case for a policy/practice that will facilitate adaptation to and/or mitigation of climate change at one of the following scales: local, state, regional, national, and global. The students would identify the specific scale/scope of the solution, evaluate its costs and benefits, and provide evidence/reasoning to evaluate the practicality and feasibility of this solution. For example, students may write about the abilities of local communities to provide mitigation strategies by hosting farmers' markets all year round to reduce the carbon footprint of produce. Students again would peer review a colleague's paper to provide feedback for revision. Students would be assessed on how well they explain and evaluate the costs and benefits of such a policy or practice. Such an exercise would allow the students to use evaluation skills (critical in higher-order thinking) in the context of climate change solutions and would also help them in course Objective 7.

\section{Objective 7: Using higher-order thinking skills, explain climate change}

Some forms of engagement focus on helping students cultivate their citizenship skills, where the application to real-life settings is important. One example of this is to have the students develop an outreach program or an informational pamphlet as proposed in Prancl's (2011) course on eating disorders. After offering many creative ideas, students finally agreed on conducting a student-run campus awareness week, in which the students in the course could demonstrate their newfound knowledge in a useful way. We suggest that an assignment requiring students to explain climate change using a medium of their choice (e.g., public service announcement, short Internet ad, comic book, digital story) is one way to approach this objective and could be developed as a final assignment for the class. A successful explanation would need to include one or more higher-order thinking skills: application, analysis, synthesis, and/or evaluation. Students yet again would peer review a colleague's product to provide feedback for revision. Students would be assessed on how effectively they explained climate change while using all seven principles learned in the course. The students' ability to use more critical-thinking skills in their explanation and improve the quality of their product through the peer review process would result in a higher performance level.

\section{All seven course objectives met}

Dole and Bloom (2009) designed an online course drawing on "how people learn" (U.S. National Research Council, 1999), a pedagogical framework grounded in empirical evidence about the efficacy of teaching and learning. In their design, students write up a short description of their initial thoughts, ideas, and opinions on the topic as the first task for the course-labeled as the 
"generating ideas" phase. Next, modules provide an iterative writing process in which students reflect on those initial short papers after they engage in the readings, lectures, online learning activities, interviews, and discussion forums. This allows students to reflect on pre-existing knowledge and experiences from their initial short papers and provides an opportunity to replace prior knowledge with new knowledge (or synthesize where appropriate)encouraging the development of critical-thinking skills and the acquisition of in-depth knowledge of the topic. Such an exercise also avoids the learning barrier identified by Hartley and colleagues (2011, p. 65) in which many students draw on informal reasoning and personal experience when asked to synthesize or apply concepts by asking them explicitly to link their initial personal views with new material from the course.

In a course on climate change and society, the first module would cover natural and anthropogenic drivers of climate change. Students would be asked to identify and classify key biophysical processes driving climate change and then explain how their own behaviors, such as the foods they eat, may impact the climate. Next, students would be asked to engage in the peer review of each other's work, as a stage of formative assessment. This can be done using an online discussion forum, thus preventing the isolated writing that takes place in a traditional course design, as consistent with Pearson's suggestions (2010). Finally, based on peer and instructor comments, students would revise their paper and resubmit it for a grade. These iterative mechanisms are opportunities for students to learn the principles of problem solving and critical thinking, much in the way that inquiry is traditionally approached in academic scholarship. In such a course, each module would focus on a course objective with the last module, building on all other modules, requiring students to explain climate change to a lay audience (see Objective 7, above).

\section{Conclusion}

Climate change educators are faced with the daunting task of making complex scientific research accessible to students in a succinct way. In order for students to be climate literate, they need to understand social, physical, and biological processes. Further, given that climate change and society is a new pedagogical topic, most of the educational investment to date has been in online tools and activities. Such resources can be a great advantage for fostering social science students' learning of biophysical and social aspects of climate change. Therefore, we believe an online setting is a valuable design for climate education in the social sciences. Here we have sketched an initial approach making use of exercises supported by research in the literature and in many cases making use of online resources for learning about climate change. Of course, the literature 
and the online tools will continue to evolve. But we believe our general points are robust. The challenges of incorporating material from the physical and biological sciences into a social science course make active learning especially valuable, and online materials can be useful tools for facilitating this learning.

\section{References}

Anderson, W. L., \& Krathwohl, D. R. (2001). Taxonomy for learning, teaching and assessing: A revision of Bloom's taxonomy of educational objectives. New York: Longman.

Bataineh, M. Z. (2015). Think-pair-share, co op-co op and traditional learning strategies on undergraduate academic performance. Journal of Educational and Social Research, 5(1), 217.

Batzli, J. M., Ebert-May, D., \& Hodder, J. (2006). Bridging the pathway from instruction to research. Frontiers in Ecology and the Environment, 4(2), 105-107.

Biggs, J. (1999). What the student does: Teaching for enhanced learning. Higher Education Research \& Development, 18(1), 57-75.

Bloom, B. S. (1956). Taxonomy of educational objectives: The classification of educational goals. New York: McKay.

Boettcher, J. V., \& Conrad, R. M. (2010). The online teaching survival guide: Simple and practical pedagogical tips. San Francisco, CA: Jossey-Bass.

Boyes, E., \& Stanisstreet, M. (2001). Plus ca change, plus c'est la meme chose?: School students' ideas about the 'greenhouse effect' a decade on. Canadian Journal of Environmental Education, 6, 77-101.

Christiansen, L., \& Fischer, N. (2010). Teaching urban sociology and urban sustainability on two feet, two wheels, and in three cities: Our experience teaching sustainable cities in North America. Teaching Sociology, 38(4), 301-313.

Clark-Ibáñez, M., \& Scott, L. (2008). Learning to teach online. Teaching Sociology, $36(1), 34-41$.

Coyle, K. (2005). Environmental literacy in America: What ten years of NEETF/ Roper Research and related studies says about environmental literacy in the U.S. Washington, DC: National Environmental Education and Training Foundation. 
Čuček, L., Klemeš, J. J., \& Kravanja, Z. (2012). A review of footprint analysis tools for monitoring impacts on sustainability. Journal of Cleaner Production, 34, 9-20.

Dole, S., \& Bloom, L. (2009). Online course design: A case study. International Journal for the Scholarship of Teaching and Learning, 3(1), 1-11.

Dowell, W. (2006). Throwing the sociological imagination into the garbage: Using students' waste disposal habits to illustrate C. Wright Mills's concept. Teaching Sociology, 34(2), 150-155.

Erickson, L. E., \& Erickson, P. A. (2013). Predicting student performance using online one-minute papers. Journal for Economic Educators, 13(1), 6-13.

Godfrey, P.C. (2015). Teaching society and climate change: Creating an 'earth community' in the college classroom by embodying connectedness through love. Journal of Sustainability Education, March.

Hamilton, L. (2012). Communicating climate science, the Internet may be the key. Climate Science \& Policy. Retrieved from www.climatescienceandpolicy. eu/2012/03/communicating-climate-science-the-internet-may-be-the-key

Hartley, L. M., Wilke, B. J., Schramm, J. W., D’Avanzo, C., \& Anderson, C.W. (2011). College students' understanding of the carbon cycle: Contrasting principle-based and informal reasoning. BioScience, 61(1), 65-75.

Howard, J. R. (2010). 2009 Hans O. Mauksch address: Where are we and how did we get here? A brief examination of the past, present, and future of the teaching and learning movement in sociology. Teaching Sociology, 38(2), 81-92.

Kirk, K. B., Gold, A. U., Ledley, T. S., Sullivan, S. B., Manduca, C. A., Mogk, D. W., \& Wiese, K. (2014). Undergraduate climate education: Motivations, strategies, successes, and support. Journal of Geoscience Education, 62(4), 538-549.

Kortemeyer, G. (2007). Correlations between student discussion behavior, attitudes, and learning. Physical Review Special Topics - Physics Education Research, 3, 010101.

Marquart-Pyatt, S., Shwom, R. L., Dietz, T., Dunlap, R. E., Kaplowitz, S. A., McCright, A. M., \& Zahran, S. (2011). Understanding public opinion on climate change: A call for research. Environment, 53(4), 38-42. 
McCright, A. M. (2012). Enhancing students' scientific and quantitative literacies through a sociological inquiry-based learning project on climate change. Journal of the Scholarship of Teaching and Learning, 12(4), 86-102.

McCright, A. M., \& Dunlap, R. E. (2011). The politicization of climate change and polarization in the American public's views of global warming, 20012010. The Sociological Quarterly, 52, 155-194.

McCright, A. M., O'Shea, B. W., Sweeder, R. D., Urquhart, G. R., \& Zeleke, A. (2013). Promoting interdisciplinarity through climate change education. Nature Climate Change, 3, 713-716.

McKinney, K. (2010). Distance learning in sociology: Some example SoTL work. Teaching/Learning Matters: ASA's Newsletter for the Section on Teaching Learning in Sociology, 39(1), 1-2.

McKinney, K., Howery, C. B., Strand, K. J., Kain, E. L., \& Berheide, C. W. (2004). Liberal learning and the sociology major updated: Meeting the challenge of teaching sociology in the twenty-first century. A Report of the ASA Task Force on the Undergraduate Major, Washington, DC: American Sociological Association.

Obach, B. K. (2009). Consumption, ecological footprints and global inequality: A lesson in individual and structural components of environmental problems. Teaching Sociology, 37(3), 294-300.

Paul, R. W., Elder, L., \& Bartell, T. (1997). California teacher preparation for instruction in critical thinking: Research findings and policy recommendations (California Commission on Teacher Credentialing). Sacramento, CA: Foundation for Critical Thinking.

Pearson, F. A. (2010). Real problems, virtual solutions: Engaging students online. Teaching Sociology, 38(3), 207-214.

Pedersen, D. E. (2010). Active and collaborative learning in an undergraduate sociological theory course. Teaching Sociology, 38(3), 197-206.

Persell, C. H. (2004). Using focused web-based discussion to enhance student engagement and deep understanding. Teaching Sociology, 32(2), 61-78.

Phelan, L. (2012). Assessment is a many-splendoured thing: Fostering online community and lifelong learning. European Journal of Open, Distance and E-Learning, 2012/I. Retrieved from www.eurodl.org/index.php?p=archives \&year $=2012$ \&halfyear $=1$ \&article $=488$ 
Prancl, M. (2011). Raising awareness: Incorporating a student-run campus awareness week in course objectives. Teaching Sociology, 39(1), 88-102.

Reynolds, T. W., Bostrom, A., Read, D., \& Morgan, M. G. (2010). Now what do people know about global climate change?: Survey studies of educated laypeople. Risk Analysis, 30(10), 1520-1538.

Roper, A. (2007). How students develop online learning skills. Educause Quarterly, 1, 62-65.

Sterman, J. D., \& Sweeney, L. B. (2007). Understanding public complacency about climate change: Adults' mental models of climate change violate conservation of matter. Climatic Change, 80(3-4), 213-238.

Swan, K., Shen, J., \& Hiltz, S. R. (2006). Assessment and collaboration in online learning. Journal of Asynchronous Learning Networks, 10(1), 45-62.

U.S. Global Change Research Program. (2009). Climate literacy: The essential principles of climate science-A guide for individuals and communities. Washington, DC: Change Research Program.

U.S. National Research Council. (1999). How people learn: Brain, mind, experience, and school. Washington, DC: National Academies Press.

U.S. National Research Council. (2007). Taking science to school: Learning and teaching science in grades $K-8$ (Committee on Science Learning, Kindergarten through Eighth Grade). Washington, DC: National Academies Press.

U.S. National Research Council. (2010a). Advancing the science of climate change. Washington, DC: National Academies Press.

U.S. National Research Council. (2010b). Climate stabilization targets: Emissions, concentrations, and impacts over decades to millennia. Washington, DC: National Academies Press.

U.S. National Research Council.(2011). Climate change education: Goals, audiences, and strategies - A workshop summary (Board on Science Education, Division of Behavioral and Social Sciences and Education). Washington, DC: National Academies Press.

Wright, E. R., \& Lawson, A. H. (2005). Computer mediated communication and student learning in large introductory sociology classes. Teaching Sociology, 33(2), 122-134. 
This text is taken from Human Ecology Review, Volume 21, Number 2, 2015, published 2015 by ANU Press, The Australian National University, Canberra, Australia. 